\title{
Exploring the motivations for garden bird feeding in south-east England
}

\author{
$\underline{\text { David N. Clark }}^{1}$, Darryl N. Jones $^{2}$ and $\underline{\text { S. James Reynolds }}^{1,3}$
}

\begin{abstract}
The feeding of wild birds in domestic gardens is one of the most widespread and popular forms of human-wildlife interaction throughout the Western World. The increasing recognition of the benefits to human health and well-being of contact with nature, especially in an increasingly urbanized world, reveals the need for a greater understanding of why we engage in bird feeding. This will undoubtedly result in enhanced benefits of feeding to both people and to the biodiversity it supports. Our study aimed to explore the motivations behind wild bird feeding in south-east England through both qualitative and quantitative approaches. This involved a two-phase process: first, the dimensions of involvement were ascertained through semistructured interviews with 30 people engaged in feeding. Interrogation of their responses was used to construct an online questionnaire. A total of 563 respondents completed this survey. Analysis of their responses discerned a series of themes with the most salient being based on or directed toward: pleasure, bird survival, nurture, education of children, and connection with nature. These findings reveal that bird feeding is underpinned by a complex array of motivations and influences involving both personal and environmental benefits.
\end{abstract}

Key Words: food supplementation; human-wildlife interactions; qualitative surveys; questionnaire

\section{INTRODUCTION}

Although the intentional provisioning of wild birds has probably been practiced in many western countries for centuries (Cocker and Tipling 2014, Reynolds et al. 2017, Jones 2018), until only a few decades ago the practice was largely opportunistic and spontaneous (Baicich et al. 2015, Jones 2018). Although there is evidence that a more organized and planned form of wild bird feeding became established in some parts of the United Kingdom (UK) following prolonged periods of extreme weather in the late 1890 s with the development and use of bird tables and seed hoppers (Allen 1976, Callahan 2014), the typical practice remained one of providing kitchen food scraps during winter, the proverbial "crumbs on the snowy window sill" (Allen 1976). An interpretation of historical newspaper articles from this period indicates a clear motivation toward relieving the suffering of the birds and improving their chances of survival (Jones 2018).

Feeding kitchen scraps to birds is still widespread but bird provisioning in the UK, the USA, and elsewhere has developed into a multimillion-dollar industry practiced by millions of people. For example, approximately $60 \%$ of British households are engaged in feeding (Fuller et al. 2008), providing an estimated 165,000 tons of seed annually to a wide range of species (Clark 2013). The popularity of the practice, actively promoted by bird and conservation organizations, has led to a proliferation of products and the emergence of an industry in the UK generating approximately US $\$ 440$ million annually (Clark 2013). Bird feeding practices in the UK, i.e., the availability of seeds, seed mixes and related products, seasonal versus year-round feeding, the regularity, and planned nature of the provisioning, raise many questions about the motivations of human participants.

The collective scale of private gardens in the UK represents one of the largest of wildlife habitat types (Cannon 1999). Supplementary feeding in gardens is potentially beneficial for birds (https://www.rspb.org.uk/get-involved/activities/birdwatch/ results/) and with the increasing intensification of land use in rural areas and concurrent declines in populations of many small bird species (Siriwardena et al. 2012), the role of gardens in providing overwintering and breeding habitat is becoming widely appreciated (Davies et al. 2012). Given its scale and popularity, wild bird feeding is almost certainly the most important and potentially malleable form of gardening for wildlife practices (Fuller et al. 2008, Jones and Reynolds 2008). However, the practice of bird feeding can also be detrimental to birds, for example by facilitating transmission of diseases between birds visiting feeding stations (Lawson et al. 2018). Thus, obtaining a detailed and reliable perspective on the motivations associated with bird feeding is timely (Jones 2011).

The growing appreciation of the many human benefits, both physical and psychological, associated with various levels of interaction with nature (Keniger et al. 2013, Cox and Gaston 2016), and a concern that in an increasingly urbanized world these interactions are decreasing (Cox and Gaston 2018), provide important perspectives on the need for a better understanding of the motivations for bird feeding. There are few activities offering a direct interaction with wild animals as straightforward as the filling of a feeder in a private garden (Chapman 2015). The pleasure associated with observing birds at close quarters, as well as supporting birds, especially in winter, have anecdotally been regarded as self-evident motivations for feeding birds (Hiesemann 1908, Soper 1965, Glue 1982). Scientific interest in these issues has gathered pace more recently. Rollinson et al. (2003) surveyed people feeding wildlife in Brisbane, Australia, and found that they believed that it benefitted the wildlife recipients. Howard and Jones (2004) were the first to investigate specifically the motivations of people engaged in wild bird feeding using both qualitative and quantitative surveys of the Australian feeding public. More recently, Galbraith et al. (2014) employed a postal survey among New Zealand feeding participants, and Schreiber (2010) an online survey of members of the British Trust for Ornithology (BTO) in the UK; both studies confirming that a clear majority of respondents was motivated primarily by the

${ }^{1}$ School of Biosciences, University of Birmingham, Birmingham, UK, ${ }^{2}$ Environmental Futures Research Institute, Griffith University, Brisbane, Australia, ${ }^{3}$ Army Ornithological Society (AOS), Aldershot, UK 
pleasure associated with feeding birds. This latter study also found that a desire to assist birds to survive through winter, as well as simply observing the bird's behavior, were strong drivers. Similarly, Chapman (2015) used a range of social science approaches to find that garden bird feeding (again, among BTO members) involved a strong moralistic element among the participants, reflecting a duty of care toward the birds and an attitude of responsibility toward their welfare.

A more detailed study by Cox and Gaston (2016) undertook an interview-based investigation of motivations among residents living in three towns near London in the UK. They compared people who did not feed, those who fed irregularly, and those who fed regularly, and found a strong relationship between level of participation and feelings of relaxation and connectedness with nature.

A more complete understanding of the motivations underlying bird feeding would facilitate communication of best practice among the bird feeding public while also developing routes for engagement with nonbird feeding citizens. Thus, the aim of this study was to attempt a detailed identification and analysis of all of the major motivations for feeding wild birds that operate alongside the themes already found. To achieve this, a combination of qualitative and quantitative techniques was used to question bird feeding participants in south-east England.

\section{METHODS}

To explore the complexity of patterns and responses associated with the practice of wild bird feeding, both quantitative and qualitative approaches were employed (Robson 2002). This mixed-methods program enhances the possibility of discerning perspectives that were not anticipated while allowing for subsequent statistical analyses (Bryman 2006). Both components of the research were approved by the University of Birmingham Human Ethics Committee (ERN/13-0160). All respondents were over 16 years of age and residents of the UK. There was no discrimination on the basis of ethnicity or social status although minimum quotas of participants of both sexes and across different age classes were required in the qualitative study. It was assumed that respondents in the quantitative study had access to a computer.

\section{Qualitative study: survey participants and procedure}

The qualitative component was undertaken to understand the motivations and triggers for feeding birds. Although qualitative approaches have foundations in health, social, and education research (Denzin and Lincoln 1998), they are increasingly being used in conservation research, particularly when interactions occur between humans and wildlife (Perez et al. 2011). These approaches allow respondents to be flexible and expansive in their answers compared to questionnaire data, which often provide more prescriptive and closed responses to lines of inquiry (Schuman and Presser 1979). An in-depth format was selected to allow respondents to be interviewed at home, providing an informal environment and context for the discussion.

Thirty in-depth interviews were performed during the winter of 2012/2013. Interviews were undertaken with adults who had fed birds in the last week at their home. Respondents were recruited using advertisements placed on the London Wildlife Trust (LWT) website and in Parent and Friends newsletters of primary schools local to DC in East Dulwich, a suburb within south-east London. The interviews were split evenly between male and female (15 of each), and between younger ( $\leq 50$ years of age) and older $(>50$ years of age) respondents.

A semistructured questionnaire guide was used to direct the interviews. Responses to two main issues were sought during the interviews: (1) the respondent's practice of bird feeding (including what was fed, when and how often), and (2) their motivation for engaging in bird feeding. The duration of the interviews was between 45 and 90 minutes. This period included a warm-up phase to allow the respondent and interviewer to become acquainted and sufficient time to explore the topics fully (Robson 2002). For each of the interviews, a summary of the original notes made at the time was completed by DC which included relevant verbatim quotes.

\section{Quantitative study: survey participants and procedure}

Quantitative information was obtained through the use of an online questionnaire. This consisted of four sections covering: (1) the practice of bird feeding; (2) the triggers that lead to it (what influenced people to feed birds); (3) the possible reasons people identified as to why they fed birds (their motivations); and (4) standard demographic details (Appendix 1).

The questionnaire was initially tested informally with six local bird feeding participants and apart from the correcting of typographical errors, no revisions were made before the questionnaire was uploaded onto the internet through the Survey Monkey ${ }^{\odot}$ (http://www.surveymonkey.co.uk) website. Respondents were recruited using advertisements placed in publications and websites of a variety of organizations including Wildlife Trusts, Royal Society for the Protection of Birds (RSPB) groups, BTO groups, and resident fora and park-friends groups. Respondents were then emailed an outline of the project and an invitation to participate in the survey through an attached link. These emails also included descriptions of procedures and reassurances of privacy.

\section{Statistical analyses}

The motivations section of the questionnaire employed (Appendix 1) a series of statements (derived from the findings of the interviews), which respondents agreed or disagreed with on a Likert scale of 1 to 10 where $1=$ strongly disagree and $10=$ strongly agree (Weitjers et al. 2010). All statistical analyses were conducted in $\mathrm{R}$ version 2.11.1 ( $\mathrm{R}$ Core Team 2010). Chi-square tests were used to examine differences between groups of respondents split by age, sex, geographical location, or wildlife group membership. Fisher's exact tests were employed when the number of responses was $\leq 5$ at any point on the Likert scale. An alpha threshold of 0.05 was used. If statistical significance was found, posthoc analyses using the standardized residuals identified differences between groups. Further posthoc analyses were performed when necessary to discern statistical significance between groups by collapsing the contingency tables from $10 \times 2$ to $2 \times 2$ (Larson and Farber 2010). When collapsing tables the Yates' continuity correction for one degree of freedom was automatically employed in $\mathrm{R}$. 


\section{RESULTS}

\section{Qualitative stage}

Upon the completion of the qualitative interviews, a detailed subjective assessment of the notes was undertaken by DC to identify themes for development of the subsequent questionnaire. Identification was based on the language used (e.g., "I feed birds for their survival" was categorized as "bird survival;" "I like to see things grow" as "nurture;" "I see them as my pets" as "companionship;" etc.). Evaluating the responses to the motivations component of the interviews of bird feeding participants indicated that many respondents often had several motivations to which they attached different levels of importance. Nine major motivational themes were identified from the qualitative responses and these were incorporated into specific questions in the quantitative questionnaire. These themes are outlined here along with indicative quotations from respondents.

\section{Pleasure}

By far the most frequently mentioned motivation was that of pleasure, with almost all interviewees mentioning this $(93 \%, \mathrm{n}=$ 28), a response equally forthcoming across age groups and genders:

I just love watching them (female older A).

I have to say the main reason is really selfish. It's for my pleasure (male younger $\mathrm{C}$ ).

This pleasure appeared to be associated with both seeing and hearing birds. The movement, behavior, and differences between the species all added to the response:

When I hear birdsong at the start of the day it gives me optimism and a spring in my step (female younger A).

If there is more than one species I get engrossed, for example watching the Greenfinches squeeze their way in (female older B).

Several respondents spoke of how they become disconnected from their daily tasks and routines while observing birds at their feeders:

I sit at the front watching birds. I can sit for an hour and then my partner takes over in case I miss something. I become oblivious to other things...it's like when you relax and all the stress goes out of you (male older D).

It's like staring into a fire or when you look at a fountain (female older C).

\section{Survival}

Fifty-seven per cent $(n=17)$ of respondents spoke in terms of being motivated to aid and conserve birds, typically in terms of nourishment, the provision of alternative food sources, or as an aid to winter survival:

I want species to continue. It is something I can do for nature. I can't help out the lions in Africa but I can help out the birds (female older D).

It is the conservation element. I want them to survive the winter. I am aware of a need to support them especially in an urban environment (male older C).
Connecting with nature

The theme interpreted as "connecting with nature" was the third most mentioned motivation $(40 \%, \mathrm{n}=12)$ with typical comments including:

I enjoy wildlife anywhere. It's like bringing the countryside to your garden (female younger B).

It's the closest you can get to wildness (male older E).

Nurturing

A theme encapsulated as "nurturing" was identified as another dimension of bird feeding:

I live on my own. The children have grown up. I have no grandchildren. I have no job now that I am retired. Ineed something to nurture, to sustain life and watch life grow (female older B).

They are my babies (female older E).

\section{Educating children}

For interviewees with children it was noted that they often spoke of wanting their child/children to be educated about birds and nature in their own family environment. For some this was seen as part of a family tradition:

[I feed the birds] as education for the children (female younger $\mathrm{C}$ ).

Having a child to pass on the tradition (female younger D).

Making Amends

Numerous respondents $(33 \%, \mathrm{n}=10)$ expressed a degree of guilt as to how humans have treated the environment and suggested that feeding offered a way of making amends. These feelings appeared to be particularly prevalent among younger respondents:

[Feeding birds is] a way of showing that there is a way of doing something for what we humans have done (male younger A).

Now things have really changed we seem to be losing so many species and gardens are so different and then there's climate change. We have to do something about it (male younger B).

We need to compensate for what we humans have done and do (female younger E).

\section{Personal Atonement}

A separate, yet closely related, theme to this generalized atonement was identified as personal atonement, encapsulating a respondent's desire to contribute personally to mitigating environmental damage that they had personally caused:

The whole area of sustainability is important with me to live within my resources (male older $\mathrm{A}$ ).

A way of recycling (female younger B). 


\section{Companionship}

The potential for some form of interaction or companionship with birds visiting their gardens was mentioned by several interviewees:

I am at home most days and they keep me company (female older E).

To tell you the truth I don't know what I would do without them. I have to keep feeding them so I can attract them (male older B).

\section{Not Wasting Food}

Finally, interviewees mentioned the provisioning of kitchen scraps to birds to not waste food:

My grandma's austerity is with me today. Because of rationing and harder times, she did not waste a thing. Feeding birds was part of this (female older F).

To not waste our food (male younger $\mathrm{C}$ ).

\section{Influences and Triggers}

During the qualitative stage respondents were given the opportunity to describe the influences and triggers for their bird feeding by exploring their personal history of the pastime. Although a large number of these were mentioned, the three most often reported were: parents $(57 \%)$, having a garden $(53 \%)$, and grandparents (43\%), exemplified in the following quotations:

Dad was inquisitive and taught us to engage and look at things. We were constantly being told about the birds (older female).

It was when we got this place. The first time that we had a garden, it made me think about the birds (younger female).

\section{Quantitative stage}

\section{Participants: demographics and locations}

The online questionnaire was available for three months (March to May 2013) and was completed by a total of 563 people. Of these, $62 \%$ of respondents were female and $38 \%$ were male; $57 \%$ were $>50$ years of age and $43 \%$ were between 16 and 50 years old. There was a distinct bias toward respondents being "white" with $87.7 \%$ categorizing themselves as "white British" and 8.2\% as "white other;" only $2.2 \%$ of respondents described themselves otherwise ( $1.9 \%$ declined to respond to this question). Although the questionnaire was open to respondents from across the UK, the sample was strongly biased toward London (48.1\%) and the south-east of England (29.4\%). Respondents self-described their residence as being mainly in either urban and suburban areas $(76 \%)$, or in the countryside and villages $(24 \%)$. Self-assessed garden sizes of the participants indicated that $25 \%$ had small gardens, 45\% had medium-sized gardens, and 30\% had large gardens (based on the RSPB's criteria used in the Big Garden Birdwatch; Chandler 2011). Approximately half of respondents $(47 \%)$ were members of environmental organizations such as the RSPB, the BTO, or local wildlife trusts.
Feeding practices

Feeding regularity differed across respondents with $46 \%$ stating that they fed daily, $33 \%$ attempting to feed every day without $100 \%$ success, and $20 \%$ feeding occasionally (Appendix 1). There was no significant gender difference in regularity of feeding $\left(\chi^{2}=\right.$ $0.84, \mathrm{df}=1, p=0.66$ ). There was, however, a significant difference in the regularity of feeding between age groups with older respondents being more diligent in their feeding habits $\left(\chi^{2}=31.96\right.$, $\mathrm{df}=1, p<0.01)$ and being more likely to feed every day $(\mathrm{z}=2.20$, $p<0.05)$ than younger respondents. Similarly, member respondents were significantly more inclined to feed than nonmember respondents $\left(\chi^{2}=25.17, \mathrm{df}=1, p<0.01\right)$ and also more likely to feed daily $(\mathrm{z}=2.50, p<0.05)$. Almost all $(98.4 \%)$ respondents fed in the winter with a reduction (to $70.5 \%$ ) in feeding during the summer. However, there was a clear majority of respondents who fed year-round.

\section{Motivational themes: quantitative comparison}

Table 1 shows the number of online survey respondents who answered the questions on motivational themes, and the median score derived from the 10-point Likert Scale. The relative significance of pleasure, bird survival, nurturing, connection with nature, and education of children as motivators for feeding birds is presented in Figure 1. For each of these themes, over $80 \%$ of respondents gave very high ratings (i.e., $\geq 6$ ). In contrast, the themes of making amends, personal atonement, companionship, and not wasting food had more mixed responses with a majority receiving scores of $\leq 5$ (Fig. 1).

Table 1. Median Likert scores from $\mathrm{n}$ respondents to a quantitative survey (Supplementary information, Appendix 1) investigating the motivational themes for feeding birds by the general public in south-east England in 2012.

\begin{tabular}{lcc}
\hline \hline Motivation & $\mathrm{n}$ & Median score $^{\dagger}$ \\
\hline Pleasure & 557 & 10 \\
Bird survival & 557 & 10 \\
Nurture & 557 & 9 \\
Children's education & 185 & 9 \\
Connect with nature & 553 & 8 \\
Making amends for environmental & 557 & 5 \\
damage & 555 & 4 \\
Atoning for personal environmental & & 4 \\
damage & 552 & 3 \\
Companionship & 553 & \\
Not wasting food & & \\
†The Likert scale was used from 1 to 10 where $1=$ strongly disagree and \\
10 = strongly agree.
\end{tabular}

The statistical comparisons for the four variables of gender, age, location, and membership status are summarized in Table 2. There were significant differences in responses between groups split according to these four variables: females were more likely than males to express nurture and education of children as motivations; members were more likely than nonmembers to express bird survival, connecting with nature, making amends, personal atonement, and companionship as motivations; both older respondents and London respondents were more likely than younger respondents and non-Londoners, respectively, to express companionship as a motivation. 
Table 2. Summary of Chi-squared tests comparing frequency distributions of support for the 10 Likert scale levels for gender (male vs female), age ( $<50$ years vs $>50$ years), location (London vs non-London), and memberships status (member vs nonmember) in explaining the motivations of the public feeding birds in south-east England in 2012.

\begin{tabular}{lcccc}
\hline \hline Motivation & Gender & Age & Location & Membership \\
\hline Pleasure & $\mathrm{NS}^{\dagger}$ & $\mathrm{NS}$ & $\mathrm{NS}$ & $\mathrm{NS}$ \\
Survival & $\chi^{2}=20.14, \mathrm{df}=9, p<0.05$ & $\mathrm{NS}$ & $\mathrm{NS}$ & $\chi^{2}=25.46, \mathrm{df}=9, p<0.01$ \\
Nurturing & $\chi^{2}=22.23, \mathrm{df}=9, p<0.01$ & $\mathrm{NS}$ & $\mathrm{NS}$ & $\mathrm{NS}$ \\
Connecting & $\chi^{2}=18.63, \mathrm{df}=9, p<0.05$ & $\mathrm{NS}$ & $\mathrm{NS}$ & $\chi^{2}=29.30, \mathrm{df}=9, p<0.01$ \\
Education & $\mathrm{NS}$ & $\mathrm{NS}$ & $\mathrm{NS}$ & $\mathrm{NS}$ \\
Making amends & $\chi^{2}=22.71, \mathrm{df}=9, p<0.01$ & $\mathrm{NS}$ & $\mathrm{NS}$ & $\chi^{2}=26.15, \mathrm{df}=9, p<0.01$ \\
Personal atonement & $\chi^{2}=23.35, \mathrm{df}=9, p<0.01$ & $\mathrm{NS}$ & $\mathrm{NS}$ & $\chi^{2}=28.45, \mathrm{df}=9, p<0.01$ \\
Companionship & $\mathrm{NS}$ & $\chi^{2}=40.91, \mathrm{df}=9, p<0.01$ & $\chi^{2}=25.53, \mathrm{df}=9, p<0.01$ & $\chi^{2}=32.34, \mathrm{df}=9, p<0.01$ \\
Not wasting food & $\mathrm{NS}$ & $\mathrm{NS}$ & $\mathrm{NS}$ & $\mathrm{NS}$ \\
\hline
\end{tabular}

${ }^{\dagger} \mathrm{NS}$ is not significant at an alpha threshold of 0.05 .

Fig. 1. Frequency distributions of respondent scores on a Likert scale of 1 to 10 (where $1=$ strongly disagree and $10=$ strongly agree) when asked about the importance of various motivational themes (a) to (i) in their bird feeding participation in south-east England in 2012.

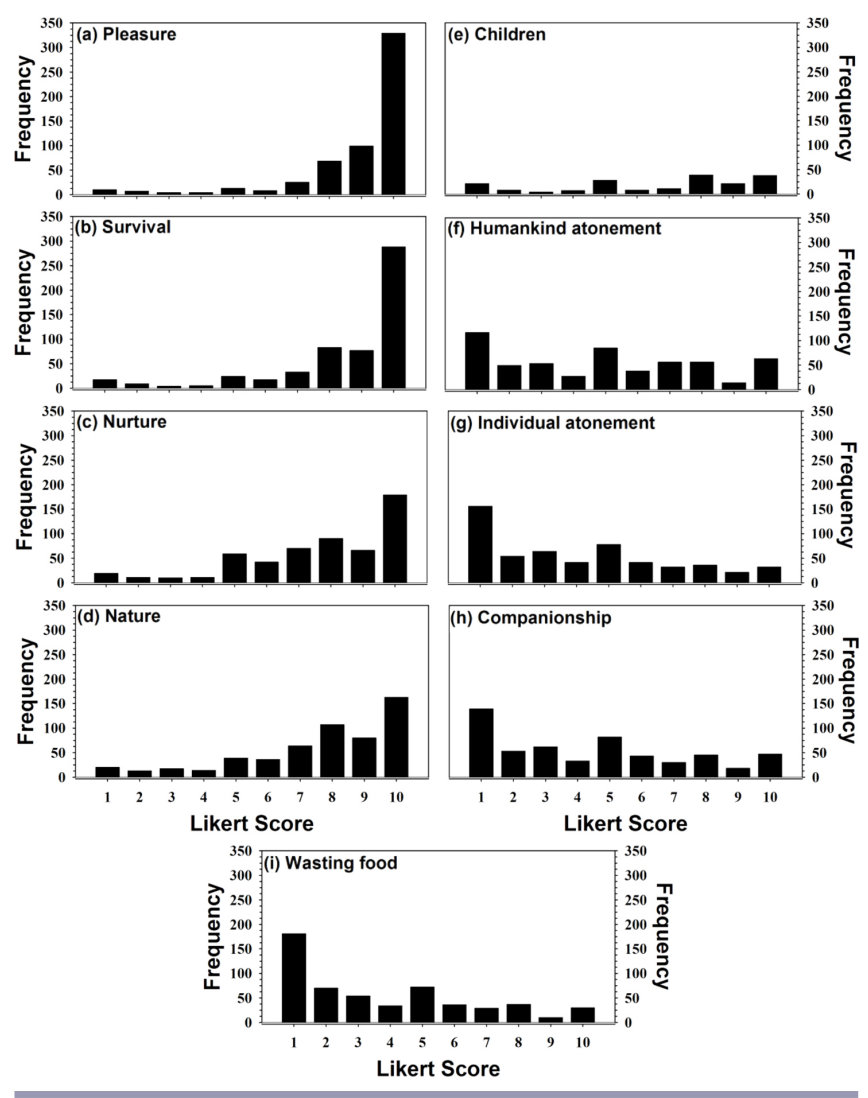

\section{Influences and triggers}

There were similarities with the qualitative results in that gardens and parents were important influences in triggering their willingness to feed birds, indicated by $81 \%$ and $40 \%$ of respondents, respectively. The influence of grandparents, however, was much lower, mentioned by only $8 \%$ of respondents.
Significantly, conservation organizations, particularly the RSPB, were nominated as the second most important influence by exactly half of all respondents.

\section{DISCUSSION}

Continued urbanization potentially decreases opportunities for residents to interact with nature through loss of green habitat, breaks in connectedness of habitat, and the increasing focus on indoor urban living (Bratman et al. 2012). Furthermore, there is a growing concern that this disconnect leads to an extinction of experience in future generations (Soga et al. 2015) and environmental generational amnesia (Hartig and Kahn 2016). This is at a time when access to nature is increasingly regarded as a critically positive element of mental health and personal wellbeing (Keniger et al. 2013, Soga et al. 2015, Cox and Gaston 2016, Reynolds et al. 2017, Jones 2018), reducing human stress levels (Hartig and Kahn 2016), and benefiting human cognitive performance (Berman et al. 2008). Furthermore, human health is arguably the most important element of ecosystem services (Sandifer et al. 2015). Despite the continuing pressures on green spaces in urban environments, gardens continue to be a significant part of the total urban green area (Colding et al. 2006) with even the smallest urban gardens able to attract birds (Burton 2000). Birds act as a mobile link species between gardens and other green spaces such as urban parks, helping to sustain bird populations (Blair 1996) while adding to their value through the provision of a diverse range of ecosystem services (Lundeberg et al. 2008). Within this context, our study demonstrates that bird feeding has the ability to provide a straightforward means of providing access and connection to nature and highlights the link between gardens and bird feeding. No other home-based activity enables regular and direct engagement with nature with relatively little financial investment (Jones 2011).

The most noteworthy general outcome of our study was the depth of feeling expressed by participants, both interviewees and survey respondents. This detection of a significant emotional component of what is a popular and familiar pastime suggests a strong and enduring engagement on the part of participants. During the interviews, highly charged emotional comments such as: "I don't know what I would do without the birds" (female older E); "It's just something I do. It is part of me" (male younger D); and "I have no-one left to nurture. They are life to me" (female older B), were expressed. These statements are strongly indicative of the 
personal and positive impact of bird feeding on the lives of many people.

Two motivations were central to these strong sentiments expressed in our study: the fundamental principle of the pleasure derived from feeding, a finding common to previous studies from a range of countries including the UK (Schreiber 2010), France (Clergeau et al. 2001), the USA and Canada (Horn and Johansen 2013), and Australia (Howard and Jones 2004); and the apparently positive enhancement on bird survival, again confirming findings from other research (Schreiber 2010, Galbraith et al. 2014, Chapman 2015). The primary contribution of our investigation was, however, a more detailed articulation of the various motivations underlying participation in bird feeding in south-east England, a capacity based on the effective combination of qualitative and quantitative methodologies.

An important element of our approach was to attempt to elicit the historical background to feeding from interviewees. Attitudes toward animals are typically influenced by traditional practices (Meng 2009) and, for some participants in this study, bird feeding was regarded as a component of a British cultural identity. Comments such as "I used to look forward to feeding the chickens and then see all the little sparrows coming down" (female older G) and "I don't have caged birds anymore. Now they come into my garden and see me" (female older $\mathrm{H}$ ) displayed a personal historical aspect to their bird feeding associated with the practices of themselves and their own families. The keeping of domestic fowl (Gallus domesticus) and caged birds, in particular, had been a popular activity in the UK historically (Shaw and Fisher 1963). Between World Wars I and II, approximately three million caged birds were kept in the UK (Messent 1977), leading to a large expansion in the availability of commercial birdseed mixes conveniently purchased from supermarkets (Callahan 2014). This commercialization and commodification of bird food for caged birds led directly to the first products packaged explicitly for wild birds (most notably, Swoop Wild Bird Food, which appeared in 1958; Callahan 2014). A further historical perspective was revealed by some older respondents in our study who referred to the motivation of not wasting food, a consequence they recognized from food rationing in World War II and the subsequent period of austerity (Callahan 2014).

Motivations such as companionship (initially associated with pets) are distinctly anthropocentric compared to the more ecocentric attitudes, which are focused on concerns for survival or nurture (Kellert and Berry 1987). The main driver of feeding, i.e., pleasure, is unequivocally self-orientated, yet appears to accompany numerous other motivations. Central to the dynamic of anthropocentric and ecocentric motivations is the expression of a need to be close to nature. This yearning for some form of interaction with wild-ness is rapidly emerging as a critically positive element of mental health and personal well-being, especially with respect to increasing levels of urbanization (Keniger et al. 2013, Soga et al. 2015). Our results revealed that having access to a garden was a primary trigger for feeding birds, emphasizing the importance of gardens in facilitating access to nature.

Furthermore, for some interviewees the practice of gardening itself was closely connected to feeding birds and a reflection of the nurture motivation. For instance, some respondents stated: "I see it as part of my whole little ecosystem that I have developed in my garden. It's not just about the birds but growing things that work together" (male younger E), and "I put my time and energy into creating little habitats rather than just adding bird feeders... more planting that is good for the birds such as berries" (male older C). Gardening has been widely reported as important for birds and other biodiversity (Cannon 1999, Lawton et al. 2010, Goddard et al. 2011). Britain has been described as a nation of gardeners (Moss 2011) with an acceleration of interest in the practice since World War II (Constantine 1981). There are, however, growing concerns about how householders carry out gardening activities (Gaston et al. 2007). The tradition of having tidy gardens, regularly mown lawns, and the removal of all weeds and other organic material, limits the food sources and shelter for wildlife (Yucel 2013). In response to this, Smith et al. (2011) noted the need for wildlife-friendly garden design and practice, and many environmental organizations and agencies are now providing detailed advice on best-practice for this type of gardening (e.g., Toms and Sterry 2008).

Our study also found that children's education was an important motivator for respondents with children. Beck et al. (2001) reported a relationship between increased knowledge and interest in wild birds and parental involvement; there is strong evidence that positive attitudes toward nature in general can be formed by experiences in childhood (Cheng and Monroe 2012) and by the frequency of these experiences (Thompson et al. 2008). Furthermore, a childhood interest in birds can lead to an enhanced concern for conservation in adulthood (Cannon 1999). Providing access to nature and thus creating positive environmental attitudes may be critical in improving the prospects of urban biodiversity and human well-being (Cheng and Monroe 2012). The challenge is dealing with a potential decrease in positive regard for wildlife associated with loss of contact with nature and changes in the amount of freedom children have to engage and explore outdoors (Balmford et al. 2002). Bird feeding, therefore, provides an accessible and home-based means for children to be exposed to nature (Cannon 1999).

This study found several significant differences between men and women in terms of their motivations to feed birds. One possible driver may be the increased need to nurture in women recognized as a key difference between the genders in many studies (e.g., van Esterik 1997, Stark 2002). Women were also more expressive in describing their emotions toward bird feeding being more likely to "forget what they are doing" (according to several respondents) and more likely to describe the experience in quasi-spiritual terms, findings, which coincide with many studies highlighting women as being more emotionally expressive than men (e.g., Stark 2002). The differences found for the bird feeding motivations of pleasure, bird survival, connecting with nature, and atonement for individual environmental damage may also be partly explained by men being more likely to display a use of less expressive language toward the environment (Kellert and Berry 1987, Cooper and Smith 2010).

Although participation in bird feeding has been found to be associated with age (Galbraith et al. 2014), it may be more appropriate to study motivations at different stages of life (e.g., establishment of first home, having family, retirement) rather than at predefined age boundaries. The age discriminators in this study were determined by simply dividing equally our qualitative 
interviewees into two broad age categories. We found that differences in motivations between these age cohorts were not as pronounced as between the sexes. There were also no differences between age cohorts in the principal motivations of pleasure, bird survival, nurture, children's education, and connection with nature. This concurs with other environmental studies (Buttel and Flinn 1978, van Liere and Dunlap 1980, Samdahl and Robertson 1989) in which age was not a good discriminator. There were differences between other motivations in which the older age cohort was more likely to feed for companionship and atone for individual environmental damage. Although not explicitly investigated during our study, it is plausible that older respondents were more likely to be living alone. Thus, the desire for companionship was more keenly felt in this age cohort of respondents. Older respondents were also more inclined to feed compared to younger respondents. There were much poorer response rates from the age groups up to 30 years of age and thus age as a discriminator was almost certainly undermined. Given the expected influence that younger people will have societally and politically in the future, we concur with many others (e.g., Cheng and Monroe 2012, Keniger et al. 2013, Soga et al. 2015) that further research is urgently required within this younger age group.

There was little difference in motivations between respondents residing in London compared to elsewhere although the latter were more likely to report companionship as a motivator, perhaps indicating their perceived or real degree of isolation. However, there were marked differences between respondents who were members of environmental groups and those who were not. Member participants were significantly more motivated to feed birds for pleasure, to assist bird survival, to connect with nature, to atone for societal and individual environmental damage, and for companionship.

\section{CONCLUSIONS}

We found the motivations for feeding birds to be multidimensional, involving nine major motivational themes: pleasure, bird survival, connecting with nature, nurture, educating children, making amends, personal atonement, companionship, and not wasting food. Garden bird feeding in south-east England, and, we would contend, throughout the UK, has deep complex cultural roots, which have been formed through historical relationships between humans and birds through domestication, pet ownership, garden stewardship, and an innate need to be close to nature. Our motivations to feed reflect this complexity displaying both altruistic and selfish motivations expressed in ecocentric and anthropocentric terms. Understanding these motivations is particularly pertinent at a time when human society is becoming more urbanized and apparently distanced from nature. We believe that the practice of bird feeding is an important part of the cultural aspect of ecosystem services and is a comparatively simple way of connecting with nature. We also demonstrated the usefulness of combining qualitative and quantitative techniques in enhancing the depth of responses provided by its participants. We acknowledge that further research is required with younger respondents both qualitatively and quantitatively, that life stage rather than age per se would be a more appropriate discriminator and that there is a need to understand in greater depth the meaning of pleasure in relation to wild bird feeding.
Responses to this article can be read online at: http://www.ecologyandsociety.org/issues/responses. php/10814

\section{Acknowledgments:}

We are grateful to Professor Graham Martin, Dr. Dan Chamberlain, and Dr. Richard Burkmar for advice and guidance. Neil Gladner, Vice President of Wild Bird Centers America, Washington, D.C., USA, Dr. David Horn at Millikin University, Decatur, IL, USA, Dr. Diane Kuehn of the SUNY College of Environmental Science and Forestry, Albany, NY, USA, and Martin George at CJ Wildlife, Upton Magna, UK all furnished useful information and provided encouragement. Matthew Coles and Sophie Johnson at HPI Research, London, UK provided useful advice about the research methodology. The London Wildlife Trust (in particular Mathew Frith) and the BTO (in particular Penny Williams) were instrumental to the success of the project in providing access to their members. Finally, we thank all of the people who kindly took part as participants in the study.

\section{LITERATURE CITED}

Allen, D. E. 1976. The naturalist in Britain: a social history. Princeton University Press, Princeton, New Jersey, USA.

Baicich, P. J., M. A. Barker, and C. L. Henderson. 2015. Feeding wild birds in America: culture, commerce, and conservation. Texas A\&M University Press, College Station, Texas, USA.

Balmford, A., L. Clegg, T. Coulson, and J. Taylor. 2002. Why conservationists should heed Pokémon. Science 295(5564):2367. http://dx.doi.org/10.1126/science.295.5564.2367b

Beck, A. M., G. F. Melson, P. L. da Costa, and T. Liu. 2001. The educational benefits of a 10-week home-based wild bird feeding program for children. Anthrozoös 14:19-28. http://dx.doi. org/10.2752/089279301786999599

Berman, M. G., J. Jonides, and S. Kaplan. 2008. The cognitive benefits of interacting with nature. Psychological Science 19 (12):1207-1212. http://dx.doi.org/10.1111/j.1467-9280.2008.02225. $\underline{\mathrm{X}}$

Blair, R. B. 1996. Land use and avian species diversity along an urban gradient. Ecological Applications 6(2):506-519. http://dx. doi.org/10.2307/2269387

Buttel, F. M., and W. L. Flinn. 1978. The politics of environmental concern: the impacts of party identification and political ideology on environmental attitudes. Environmental Behavior 10:17-36. http://dx.doi.org/10.1177/0013916578101002

Bratman, G. N., J. P. Hamilton, and G. C. Daily. 2012. The impacts of nature experience on human cognitive function and mental health. Annals of the New York Academy of Sciences 1249:118-136. https://doi.org/10.1111/j.1749-6632.2011.06400.x

Bryman, A. 2006. Integrating quantitative and qualitative research: how is it done? Qualitative Research 6:97-113. http://dx. doi.org/10.1177/1468794106058877 
Burton, R. 2000. Birdfeeder handbook. Dorling Kindersley, London, UK.

Callahan, D. 2014. A history of bird watching in 100 objects. Bloomsbury, London, UK.

Cannon, A. 1999. The significance of private gardens for bird conservation. Bird Conservation International 9:287-297. http:// dx.doi.org/10.1017/S095927090000349X

Chandler, D. 2011. The big RSPB birdwatch: get to know the birds outside your window! Bloomsbury, London, UK.

Chapman, R. 2015. Why do people feed wildlife? An international comparison. Dissertation. Griffith University, Brisbane, Australia.

Cheng, J. C.-H., and M. C. Monroe. 2012. Connection to nature: children's affective attitude towards nature. Environment and Behavior 44:31-49. http://dx.doi.org/10.1177/0013916510385082

Clark, D. 2013. A study of the motivations of the general public in feeding birds in their gardens. Thesis. University of Birmingham, Birmingham, UK.

Clergeau, P., G. Mennechez, A. Sauvage, and A. Lemoine. 2001. Human perception and appreciation of birds: a motivation for wildlife conservation in urban environments in France. Pages 69-88 in J. M. Marzluff, R. Bowman, and R. Donelly, editors. Avian ecology and conservation in an urbanizing world. Kluwer, New York, New York, USA. http://dx.doi.org/10.1007/978-1-4615-1531-9 4

Cocker, M., and D. Tipling, D. 2014. Birds and people. Random House, London, UK.

Colding, J., J. Lundberg, and C. Folke. 2006. Incorporating greenarea user groups in urban ecosystem management. Ambio 35:237-244. http://dx.doi.org/10.1579/05-A-098R.1

Constantine, S. 1981. Amateur gardening and popular recreation in the $19^{\text {th }}$ and $20^{\text {th }}$ centuries. Journal of Social History 14:387-406. http://dx.doi.org/10.1353/jsh/14.3.387

Cooper, C. B., and J. A. Smith. 2010. Gender patterns in birdrelated recreation in the USA and UK. Ecology and Society 15 (4):4. http://dx.doi.org/10.5751/ES-03603-150404

Cox, D. T. C., and K. J. Gaston. 2016. Urban bird feeding: connecting people with nature. PLOS ONE 11(7):e0158717. http://dx.doi.org/10.1371/journal.pone.0158717

Cox, D. T. C., and K. J. Gaston. 2018. Human-nature interactions and the consequences and drivers of provisioning wildlife. Philosophical Transactions of the Royal Society B: Biological Sciences 373:20170092.http://dx.doi.org/10.1098/rstb.2017.0092

Davies, Z. G., R. A. Fuller, M. Dallimer, A. Loram, and K. J. Gaston. 2012. Household factors influencing participation in bird feeding activity: a national scale analysis. PLoS ONE 7(6): e0039692. http://dx.doi.org/10.1371/journal.pone.0039692

Denzin, N., and Y. Lincoln. 1998. The landscape of qualitative research: theories and issues. Sage, London, UK.

Fuller, R. A., P. H. Warren, P. R. Armsworth, O. Barbosa, and K. J. Gaston. 2008. Garden bird feeding predicts the structure of urban avian assemblages. Diversity and Distributions 14:131-137. http://dx.doi.org/10.1111/j.1472-4642.2007.00439.x
Galbraith, J. A., J. R. Beggs, D. N. Jones, E. J. McNaughton, C. R. Krull, and M. C. Stanley. 2014. Risks and drivers of wild bird feeding in urban areas of New Zealand. Biological Conservation 180:64-74. http://dx.doi.org/10.1016/j.biocon.2014.09.038

Gaston, K. J., R. A. Fuller, A. Loram, C. MacDonald, S. Power, and N. Dempsey. 2007. Urban domestic gardens (XI): variation in urban wildlife gardening in the United Kingdom. Biodiversity Conservation 16:3227-3238. http://dx.doi.org/10.1007/s10531-007-9174-6

Glue, D. E. 1962. The garden bird book. Macmillan, London, UK.

Goddard, M. A., A. J. Dougill, and T. G. Benton. 2011. Scaling up from gardens: biodiversity conservation in urban environments. Trends in Ecology and Evolution 25:90-98. http:// dx.doi.org/10.1016/j.tree.2009.07.016

Hartig, T., and P. H. J. Kahn, Jr. 2016. Living in cities, naturally. Science 352(6288):938-940. http://dx.doi.org/10.1126/science. aaf 3759

Hiesemann, M. 1908. How to attract and protect wild birds. Witherby and Co., London, UK. http://dx.doi.org/10.5962/bhl. title. 54194

Horn, D. J., and S. M. Johansen. 2013. A comparison of birdfeeding practices in the U.S. and Canada. Wildlife Society Bulletin 37:293-300. http://dx.doi.org/10.1002/wsb.281

Howard, P., and D. N. Jones. 2004. A qualitative study of wildlife feeding in south-east Queensland. Pages 55-62 in S. Burgin and D. Lunney, editors. Urban wildlife: more than meets the eye. Royal Zoological Society of N.S.W., Sydney, Australia. http://dx.doi. org/10.7882/FS.2004.081

Jones, D. N. 2011. An appetite for connection: why we need to understand the effect and value of feeding wild birds. Emu 111:ivii. http://dx.doi.org/10.1071/MUv111n2_ED

Jones, D. N. 2018. The birds at my table: why we feed wild birds and why it matters. Cornell University Press, Ithaca, New York, USA. http://dx.doi.org/10.7591/9781501710797

Jones, D. N., and S. J. Reynolds. 2008. Feeding birds in our towns and cities: a global research opportunity. Journal of Avian Biology 39:265-271. http://dx.doi.org/10.1111/j.0908-8857.2008.04271.x

Kellert, S. R., and J. K. Berry. 1987. Attitudes, knowledge, and behaviors toward wildlife as affected by gender. Wildlife Society Bulletin 15:363-371.

Keniger, L. E., K. J. Gaston, K. N. Irvine, and R. A. Fuller. 2013. What are the benefits of interacting with nature? International Journal of Environmental Research and Public Health 10:913-935. http://dx.doi.org/10.3390/ijerph10030913

Larson, R., and B. Farber. 2010. Elementary statistics: picturing the world. Pearson, London, UK.

Lawson, B., R. A. Robinson, M. P. Toms, K. Risely, S. MacDonald, and A. A. Cunningham. 2018. Health hazards to wild birds and risk factors associated with anthropogenic food provisioning. Philosophical Transactions of the Royal Society B: Biological Sciences 373:20170091. http://dx.doi.org/10.1098/ rstb.2017.0091

Lawton, J. H., P. N. M. Brotherton, V. K. Brown, C. Elphick, A. H. Fitter, J. Forshaw, R. W. Haddow, S. Hilborne, R. N. Leafe, G. 
M. Mace, M. P. Southgate, W. J. Sutherland, T. E. Tew, J. Varley, and G. R. Wynne. 2010. Making space for nature: a review of England's wildlife sites and ecological network. DEFRA, London, UK. [online] URL: https://webarchive.nationalarchives.gov. uk/20130402170324/http://archive.defra.gov.uk/environment/biodiversity/ documents/201009space-for-nature.pdf

Lundberg, J., E. Andersson, G. Cleary, and T. Elmqvist. 2008. Linkages beyond borders: targeting spatial process in fragmented urban landscapes. Landscape Ecology 23:717. http://dx.doi. org/10.1007/s10980-008-9232-9

Meng, J. 2009. Origins of attitudes towards animals. Dissertation. University of Queensland, Brisbane, Australia.

Messent, P. R. 1977. Aviculture and the pet bird. Journal of Small Animal Practice 19:43-46. http://dx.doi.org/10.1111/j.1748-5827.1978. $\underline{\text { tb05457.x }}$

Moss, S. 2011. Birds Britannia: why the British fell in love with birds. Collins, London, UK.

Pérez, I., A. Giménez, and A. Pedreño. 2011. A qualitative examination of the social practices and representations towards a species of endangered tortoise. Wildlife Research 38:323-329. http://dx.doi.org/10.1071/WR10209

R Core Team. 2010. R: a language and environment for statistical computing. R Foundation for Statistical Computing, Vienna, Austria. [online] URL: http://www.R-project.org/

Reynolds, S. J., J. A. Galbraith, J. A. Smith, and D. N. Jones. 2017. Garden bird feeding: insights and prospects from a north-south comparison of this global urban phenomenon. Frontiers in Ecology and Evolution 5:Article 24. http://dx.doi.org/10.3389/ fevo.2017.00024

Robson, C. 2002. Real world research. Blackwell, London, UK.

Rollinson, D. J., R. A. O’Leary, and D. N. Jones. 2003. The practice of wildlife feeding in suburban Brisbane. Corella 27:52-58.

Samdahl, D. M., and R. Robertson. 1989. Social determinants of environmental concern: specification and test of the model. Environment and Behavior 21:57-81. http://dx.doi. org/10.1177/0013916589211004

Sandifer, P. A., A. E. Sutton-Grier, and B. P. Ward. 2015. Exploring connections among nature, biodiversity, ecosystem services, and human health and well-being: opportunities to enhance health and biodiversity conservation. Ecosystem Services 12:1-15. http://dx.doi.org/10.1016/j.ecoser.2014.12.007

Schreiber, L. 2010. Why we feed wild birds: a case study of BTO members' motivation for feeding birds in their gardens. Thesis. University College, London, UK.

Schuman, H., and S. Presser. 1979. The open and closed question. American Sociological Review 44:692-712. http://dx.doi. org/10.2307/2094521

Shaw, M., and J. Fisher. 1963. Animals as friends and how to keep them. Dent, London, UK.

Siriwardena, G. M., I. R. Cooke, and W. J. Sutherland. 2012. Landscape, cropping and field boundary influences on bird abundance. Ecography 35:162-173. http://dx.doi.org/10.1111/ j.1600-0587.2011.06839.x

Smith, C., D. Dawson, J. Archer, M. Davies, M. Frith, E. Hughes, and P. Massini. 2011. From green to grey: observed changes in garden vegetation structure in London, 1998-2008. London Wildlife Trust, London, UK.

Soga, M., Y. Yamaura, T. Aikoh, Y. Shoji, T. Kubo, and K. J. Gaston. 2015. Reducing the extinction of experience: association between urban form and recreational use of public greenspace. Landscape and Urban Planning 143:69-75. http://dx.doi. org/10.1016/j.landurbplan.2015.06.003

Soper, T. 1965. The bird table book. David and Charles, Newton Abbott, UK.

Stark, R. 2002. Physiology and faith: addressing the universal gender difference in religious commitment. Journal for the Scientific Study of Religion 41:495-507. http://dx.doi. org/10.1111/1468-5906.00133

Thompson, C. W., P. Aspinall, and A. Montarzino. 2008. The childhood factor: ddult visits to green places and the significance of childhood experience. Environment and Behavior 40:111-143. http://dx.doi.org/10.1177/0013916507300119

Toms, M., and P. Sterry. 2008. Garden birds and wildlife. AA Publishing, Basingstoke, UK.

Van Esterik, P. 1997. Women and nurture in industrial societies. Proceedings of the Nutrition Society 56:335-343. http://dx.doi. org/10.1079/PNS19970036

Van Liere, K. D., and R. E. Dunlap. 1980. The social bases of environmental concern: a review of hypotheses, explanations and empirical evidence. Public Opinion Quarterly 44(18):1-197. http:// dx.doi.org/10.1086/268583

Weijters, B., E. Cabooter, and N. Schillewaert. 2010. The effect of rating scale format on response styles: the number of response categories and response category labels. International Journal of Research in Marketing 27:236-247. http://dx.doi.org/10.1016/j. ijresmar.2010.02.004

Yücel, G. F. 2013. Integrating ecosystem landscapes in cityscape: birds and butterflies. Pages 263-276 in M. Ozyavuz, editor. Advances in landscape architecture. InTech, New York, New York, USA. [online] URL: http://cdn.intechopen.com/pdfs/45435/ InTech- $\% \mathrm{C} 4 \% \mathrm{~B} 0$ ntegrating ecosytem landscapes in cityscapebirds_and_butterflies.pdf 
Appendix 1. Quantitative research questionnaire.

1. This questionnaire is for people who have fed wild birds at home in their gardens or on their balcony in the last 6 months in south-east England.

It takes around 10 minutes to fill in and is part of a scientific thesis centered on feeding birds.

Your participation in the research is voluntary. You may choose not to participate and you may withdraw participation at any time. There are no penalties for not participating or for withdrawing at any time.

Protecting your privacy is paramount and no participants will be identified within the research; names and addresses are not required. Once the survey questions are submitted you will not be able to withdraw from the study and by completing the survey you will have consented for the data to be included within the study. If you are interested in receiving a summary of the research findings after the dissertation is completed (i.e. after the end of August 2013), please contact the researcher Mr David Clark at:dave@mailbox.co.uk.

Clicking on the 'agree` button below indicates that:

You have read the above information

You voluntarily agree to participate

If you do not wish to participate then please click on the 'disagree` button.

Agree

Disagree 
Question 2

When do you feed birds in your garden / on your balcony?

Winter

Spring

Summer

Autumn

Tick All That Apply

Question 3

How often do you feed the birds in your garden / on your balcony?

Every day

I try to feed every day but not with $100 \%$ success

Occasionally

Question 4

What do you feed birds in your garden / on your balcony?

Please Tick All That Apply

Peanuts

Fatballs

Sliced fruit and / or vegetables

Niger seed

Sunflower seed

Mixed seed

Leftovers

Your own prepared food for the birds

Mealworms

Other: Please Specify

Question 5

Who or what was the most important influence for you in starting to feed birds in your garden?

Please tick one box

Parents

Grandparents

Friends

Neighbours

Children

RSPB/ BTO / Wildlife Trust / conservation organisation

Newspapers / television / magazines

Having a garden

Other: please specify 
Question 6

Were there any other influences for you in starting to feed birds?

Tick as many as that apply

Parents

Grandparents

Friends

Neighbours

Children

RSPB/BTO/Wildlife Trust/conservation organisation

Newspapers / television / magazines

Having a garden

Other: please specify

Question 7

How long have you been feeding birds in your garden?

Less than 5 years

More than 5 years

Nearly all of my life

Question 8

These statements are about finer details of feeding birds. Please indicate how much you agree with them where:

$10=$ strongly agree

$1=$ strongly disagree

I have a duty to feed the birds that come to my home

There is something spiritual about feeding the birds

Feeding birds is my way of making up for all the damage we humans have done to the planet

Feeding birds is part of what I am and do

Feeding birds is a way that I can connect with nature

I like to think of the birds I feed as my birds

I feed birds to help them survive

Feeding birds for me is a way of not wasting food

Feeding birds is a way of making up for any damage I am doing to the environment

Feeding birds gives me pleasure

Sometimes I think that I would be lost without the birds, they are my friends

I like to nurture living things 
Question 9

If you have children at home, how much do you agree with the following statement?

Remember that:

$10=$ strongly agree

$1=$ strongly disagree

If you do not have children at home please go to question 10.

I feed the birds for my children to be educated about natural things

Question 10

Thinking about your feelings about feeding birds, how much do you agree with the following statements?

Again:

$10=$ strongly agree

$1=$ strongly disagree

It makes me feel grown up feeding the birds in the garden

It's not so much the type of bird but how many birds that I attract which makes me feel happy

It gives me a warm glow inside

I have no strong feelings about feeding birds; it`s just something I do

Seeing many different types of birds in the garden makes me feel happier than how many birds

I sometimes forget about what I am doing when I watch the birds in my garden

I get excited seeing a new type of bird in my garden

I feel proud that I have done something for nature and the environment

Question 11

Which three birds do you most like attracting by feeding?

Please list three

Question 12

Which three birds do you least like feeding?

Please list three

Question 13

Do you feed any other animals in your garden or on your balcony?

If so please list which animals

Question 14

Are you

Male / female 
Question 15

Your age?

$16-19$

$20-30$

$31-40$

$41-50$

$51-60$

$61-70$

$71+$

Question 16

How large is the area in which you feed?

Small from balcony size to around $10 \times 12$ metres

Medium up to $10 \times 25$ metres

Large above $10 \times 25$ metres

Question 17

Which best describes where you live?

A village

An urban centre

Suburbia

The countryside

Question 18

What is your postcode?

Question 19

Are you a member of the BTO / the RSPB / a local Wildlife Trust?

Yes

No 
Question 20

Please indicate to which occupational group the main income earner of your household belongs, or to which of the groups they best fit.

Please tick one

Owner or director of business

Senior manager

Middle manager

Junior manager

Administration / clerical

Skilled manual work

Semi and unskilled manual work

Student / full time education

Retired

Unemployed

Question 21

To which of these groups do you consider you belong?

White British

White - other

Black - Caribbean

Black - African

Black - other

Indian

Pakistani

Chinese

Would rather not say

Other: please specify

Thank you for your time and efforts in completing this questionnaire. They are much appreciated. 